\title{
PHYSICS IN DAILY LIFE: DRINK OR DRIVE
}

\author{
L.J.F. (Jo) Hermans, \\ Leiden University•The Netherlands • Email: Hermans@Physics.LeidenUniv.nl
}

$\mathrm{F}$ or most of us, the small revolution went unnoticed. When we drive our car these days, our gasoline engine is no longer running on fossil fuel, i.e., on the solar energy harvest of millions of years ago. For a few percent, it is running on the solar energy harvest of last year: on bio-ethanol, that is. For Diesel engines, it may be even more than just a few percent. In Germany, for example, up to 200000 cars have been running on pure biodiesel lately. And the European Commission's goal is that $10 \%$ of all transport fuel be biofuel by the year 2020 .

The EC may have been ill advised to set that goal. We have witnessed a dramatic increase in food prices world wide over the last years, and part of that is due to biofuels. Is the whole idea of biofuels just a hype, then?

Let us do a back-of-an-envelope calculation. Our daily food amounts to about $10000 \mathrm{~kJ} / \mathrm{day}$. In terms of oil or gasoline, that is $1 / 4$ liter per day, only a small fraction of what our cars needs as a daily diet. In other words: If adopted on a world wide scale, this idea is bound to run into problems, if we assume that the biofuel competes with food. Which is what the present, so-called first generation, does.

If we utilize not only the food-related part of plants, but the whole harvest of photosynthesis including straw and the like, we can do better. But even this 'second generation' of biofuels
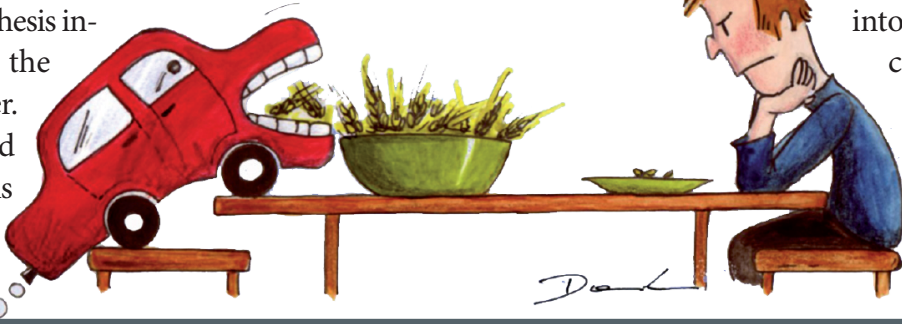

has its limits. The reason, of course, is that the overall efficiency of natural photosynthesis is low. In a typical European climate, it is somewhat below $1 \%$ as an average over the yearly solar energy influx. Which is bad news for densely populated and energy-intensive countries. Take the Netherlands, for example. Even with an optimistic photosynthesis efficiency of $1 \%$, the area needed for the total energy consumption to be based on biomass on a sustainable basis would be more than twice the total area of the country.

Granted: sooner or later we will have to rely on the sun for an appreciable part of our energy supply. But can't we do better than good old photosynthesis? Think of photovoltaic cells, for example. Crystalline silicon cells routinely have an overall efficiency of 10 to $15 \%$, while multi-junction concentrator cells achieved a record $43 \%$ in the summer of 2007. This suggests that we may be better off relying on high-tech solutions, rather than trying to meet the energy demand of the modern energy-intensive society with methods of the Middle Ages.

In any case: Should we base our future fuel consumption on bio-ethanol, we sure would run into nasty dilemmas. For example, during the reception of the $50^{\text {th }}$ anniversary of the EPS in 2018, we would face questions like 'Shall we have another glass, or shall we drive our car for another 300 meters?' -

\section{Comment/Addendum to L.J.F. Hermans, "Refueling", Europhysics News 39/1 (2008)}

I much enjoyed reading L.J.F. Hermans' article "Refueling" in the last issue of Europhysics News. It highlights how simple physics reasoning can inform us on the fundamental constraints that new (and old) technologies face. I would like to add how after identifying stumbling blocks by back-of-the-envelope estimates, it is often important to think "out of the box" (or the "box" out of the car, in this case, as we will see).

Hermans' article points out a problem with electric cars. A car driving on the highway uses about $15 \mathrm{~kW}$ (see [1] for an instructive order of magnitude estimate of the energy that a car uses). This rate of energy usage is larger than the maximum rate of recharging of $3.5 \mathrm{~kW}$ from a standard electricity outlet. Even if we build a network of high-power charge stations, it is unclear whether batteries can ever be charged at $21 \mathrm{MW}$, the rate at which we pour gasoline into our present day cars. Therefore, electric car travel is potentially plagued by long stops for charging on trips that exceed the capacity of one battery cycle. Luckily, there is a simple potential solution: Electric cars (at least on long trips) should not be refueled by charging a car-mounted battery, but by simply swapping empty batteries for full ones! The empty batteries can then be slowly recharged in a fueling station. In fact, battery exchange is at the heart of a recent proposal to build up an electric car infrastructure in Israel $[2,3]$.

Another back-of-the-envelope calculation can inform us about the required infrastructure. Cars drive on average $20000 \mathrm{~km}$ per year (this is the value that used car-sites use). If we assume an average speed of $50 \mathrm{~km} / \mathrm{h}$, cars drive about 400 hours per year, or a little more than 1 hour per day. From the above it follows that the average recharging time would then be about 4 hours per day, considerably less than the 24 hours per day available. The conclusion would be that, in principle, we would even need fewer batteries than cars.

Jan Lipfert

Faculty of Applied Sciences, Delft University of Technology, The Netherlands j.lipfert@tudelft.nl

\section{References}

[1] S. Mahajan http://arxiv.org/abs/physics/ 0512209v1 (2005)

[2] www.nytimes.com/2007/10/29/ technology/29agassi.html (2007)

[3] www.spiegel.de/wirtschaft/ 0,1518,534411,00.html (2008) 